\title{
Role of Anesthesia Team in Prehospital Care: The Hidden Treasure in Critical Settings
}

\author{
Mohammad Reza Razavizadeh ${ }^{1, *}$ \\ ${ }^{1}$ Trauma Research Center, Kashan University of Medical Sciences, Kashan, IR Iran \\ ${ }^{*}$ Corresponding author: Mohammad Reza Razavizadeh, Trauma Research Center, Kashan University of Medical Sciences, Kashan, IR Iran. Tel: +98-9133611014, \\ E-mail:mr_razavi48@yahoo.com
}

Received: April 21, 2015; Accepted: May 16, 2015

Keywords: Prehospital Care; Anesthesia; Trauma; Disaster

Undoubtedly, prehospital care has an important role in the management of trauma victims and their outcome. Before the painful event of collapsing Mehrabad international airport foyer ceiling in December 1974, there was no specified and organized system for the management and transportation of victims of different unpredictable events in our country (Iran) (1). This event motivated arranging an emergency system, which led to establishment of Emergency Medical Services (EMS) in 1978 with American experts' cooperation (2). Later, in 2002 a comprehensive medical emergency plan approved an academic course entitled "Medical Emergency" with associated (Technician) degree established in some medical universities and in 2011 admission of emergency medical technicians (EMTs) started with BS degree (3). If in the not-so-distant past shortage of manpower in this field was being challenged, Quality Improvement (QI) of EMS is a challenging necessity nowadays. Once we talk about QI, training and education are critical components that need to be addressed. Training staff competent to encounter any common and mass casualties as effective as possible is very important. Along with other professionals including emergency medicine specialists, anesthesiologists can play important roles in training students and management of trauma victims. Since anesthesiologists are professional experts in airway management, pain management, critical care, hemodynamic stabilization and resuscitation, they can direct Continuing Medical Education (CME) courses for practicing EMTs. In addition to training, the role of anesthesiologists in providing prehospital care is important (4). Many studies showed that prehospital anesthesia has been associated with functional and survival benefits (5-8). For example, it has been shown that tracheal intubation of severely injured patients could be unsafe particularly if performed without appropriate expertise, drugs, monitoring and equipment in prehospital setting (4). Hence, anesthetists could fill the gap in such situations.

On the other hand, before establishing the academic course of "Medical Emergency" in our country, many anesthesia technicians continued their education in nursing and then some of them started their work as EMT. This group of graduates (usually called anesthesia nurses) may be more effective in mass casualty settings. Mass Casualty Incidents (MCIs) (e.g. naturally occurring events like earthquake and floating or large-scale community and local accidents) may impose many victims that surpass accessible resources in their successful management. Nurse anesthesia educations, their individual clinical experiences and capabilities make them as effective as other professionals like Red Crescent personnel during MCIs. Nurse anesthetists have problem solving and critical thinking skills and are recognized experts in intravenous cannulation, vital signs monitoring, resuscitation and airway management. These capabilities and qualities are potential precious possessions for the management of mass-casualty victims (9). Emergency medical services training adjoined and supported by the anesthesia team would promote the program meeting the standards of quality, and further, ongoing evaluation and frequent program development may guarantee the quality improvement of this critical health service.

\section{References}

1. Isfahan University of Medical Sciences.. History of emergency medical services in Iran. 2014. Available from: http://emsold.mui.ac.ir/ ems-115-tarikh-667.html.

2. Bahadori MK. Emergency Medical Services In Iran: An Overview. Australasian med j. 2010;3(6):335-9.

Copyright (C) 2015, Kashan University of Medical Sciences. This is an open-access article distributed under the terms of the Creative Commons Attribution-NonCommercial 4.0 International License (http://creativecommons.org/licenses/by-nc/4.0/) which permits copy and redistribute the material just in noncommercial usages, provided the original work is properly cited. 
3. Medical Emergency Center . History of prehospital emergency in Iran. Lorestan: Lorestan university of medical sciences; Available from: http://115.lums.ac.ir/index.php?module=web_ directory\&wd_id=1630.

4. Booth A, Steel A, Klein J. Anaesthesia and pre-hospital emergency medicine. Anaesthesia. 2013;68 Suppl 1:40-8.

5. Eich C, Roessler M, Nemeth M, Russo SG, Heuer JF, Timmermann A. Characteristics and outcome of prehospital paediatric tracheal intubation attended by anaesthesia-trained emergency physicians. Resuscitation. 2009;80(12):1371-7.

6. Berlot G, La Fata C, Bacer B, Biancardi B, Viviani M, Lucangelo U, et al. Influence of prehospital treatment on the outcome of pa- tients with severe blunt traumatic brain injury: a single-centre study. Eur J Emerg Med. 2009;16(6):312-7.

7. Bernard SA, Nguyen V, Cameron P, Masci K, Fitzgerald M, Cooper DJ, et al. Prehospital rapid sequence intubation improves functional outcome for patients with severe traumatic brain injury: a randomized controlled trial. Ann Surg. 2010;252(6):959-65.

8. Klemen P, Grmec S. Effect of pre-hospital advanced life support with rapid sequence intubation on outcome of severe traumatic brain injury. Acta Anaesthesiol Scand. 2006;50(10):1250-4.

9. American Association on Nurse Anesthetists (AANA).. Professional Practice .America: American Association on Nurse Anesthetists (AANA). 